\title{
Austausch verbindet
}

- Kürzlich kehrte ich begeistert von einer auf den ersten Blick „unscheinbaren“ Veranstaltung in die Redaktion zurück: dem 1. Ergoforum Demenz in Stuttgart. Geladen hatte die Alzheimer-Gesellschaft Baden-Württemberg. Das Forum war sowohl intra- als auch interprofessionell dem informellen Austausch gewidmet und verzichtete bewusst auf ein pompöses Rahmenprogramm. Fasziniert war ich, weil tatsächlich ein intensiver Austausch stattfand. Alle konnten von den Erfahrungen der anderen lernen. Eine, wie ich finde, vielversprechende Herangehensweise, um neue Kontakte zu knüpfen und sich über die Berufsgrenzen hinaus zu vernetzen. Von diesem Veranstaltungsformat wünsche ich mir mehr!

_ Berührt hat mich in dieser Ausgabe der ganz persönliche Erfahrungsbericht von Hiltrud Gröss ab Seite 20. Dazu bin ich auf Ihr Feedback ganz besonders gespannt. Gerade wenn wir mit schwer kranken Klienten arbeiten, ist der Austausch mit Kollegen oder eine Supervision wichtig, um Erlebtes zu verarbeiten. Da das professionelle Verarbeiten von Klientenschicksalen für die eigene Psychohygiene so wichtig ist, haben wir uns für diesen Beitrag entschieden. Wir werden auch künftig diesem Thema in loser Folge Raum geben.

_ Vom 3. bis 5. Oktober finden in Stuttgart die 2. ergotage statt. Thema in diesem Jahr: „Lernen ermöglichen“. Für Sie bestimmt eine gute Gelegenheit, Neues zu lernen und - als positiven Nebeneffekt - alte Kollegen wiederzutreffen. Auch wir von der Redaktion ergopraxis werden dort vertreten sein und fiebern der Veranstaltung bereits entgegen. Wir würden uns freuen, Sie dort persönlich kennenzulernen!

Eine gute Lektüre wünscht Ihnen

Ihre

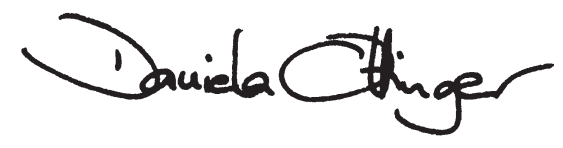

PS: Uns ist ein reger Austausch mit Ihnen wichtig. Daher bitten wir Sie diesmal in einigen Artikeln gezielt um Ihre Meinung. Mischen Sie sich in die Diskussion ein, wir freuen uns über Ihre Zuschriften! 